\title{
The Atlantic Meridional Overturning Circulation over decades to centuries
}

\author{
K. Halimeda Kilbourne \\ Boulder, USA, 23-25 May 2016
}

To make more accurate projections of future climate, we must improve our understanding of Atlantic Meridional Overturning Circulation (AMOC), its drivers and its impacts. Modern oceanographic observations of AMOC have limited record lengths, making it difficult to address important processes with timescales of decades to centuries (Buckley and Marshall 2016). Paleoceanographic data and techniques applied to Earth's recent past have a demonstrated potential to provide information about past AMOC behavior that could address questions about $\mathrm{AMOC}$ processes on these timescales and put recent changes into historical context (Alley 2007; Denton and Broecker 2008). Doing so most effectively requires coordination and cooperation across traditional disciplinary boundaries.

Two different scientific communities - modern physical oceanographers and paleoceanog raphers - came together to work on understanding AMOC over decades to centuries. We had approximately 60 attendees from nine countries, including 18 early-career scientists. One third of participants indicated in their meeting applications that they were working on the modern system, half were working on paleoceanographic questions, and the rest defied such simple characterization. During the meeting, it became clear the group represented four communities - modelers and observationalists working on the modern AMOC system, and modelers and observationalists working on the AMOC system of the past. Sometimes the lines were blurry, but there were clear differences in vocabulary, assumptions and scientific priorities. The discussions led to four main recommendations for progressing toward a better understanding of AMOC.

\section{A consistent framework between} models and observations

A factor limiting progress is the ability to make valid comparisons between paleoclimate data, model data and modern observations. AMOC in models is often based on the zonally integrated circulation in the Atlantic, and modern observational networks have been set up with this in mind. Paleoclimate proxy records, on the other hand, usually reconstruct an AMOC-related variable such as the vertical mixing in the Labrador Sea. Priority needs to be given to research and activities that move the communities toward a common standard for comparisons between observational and model data.

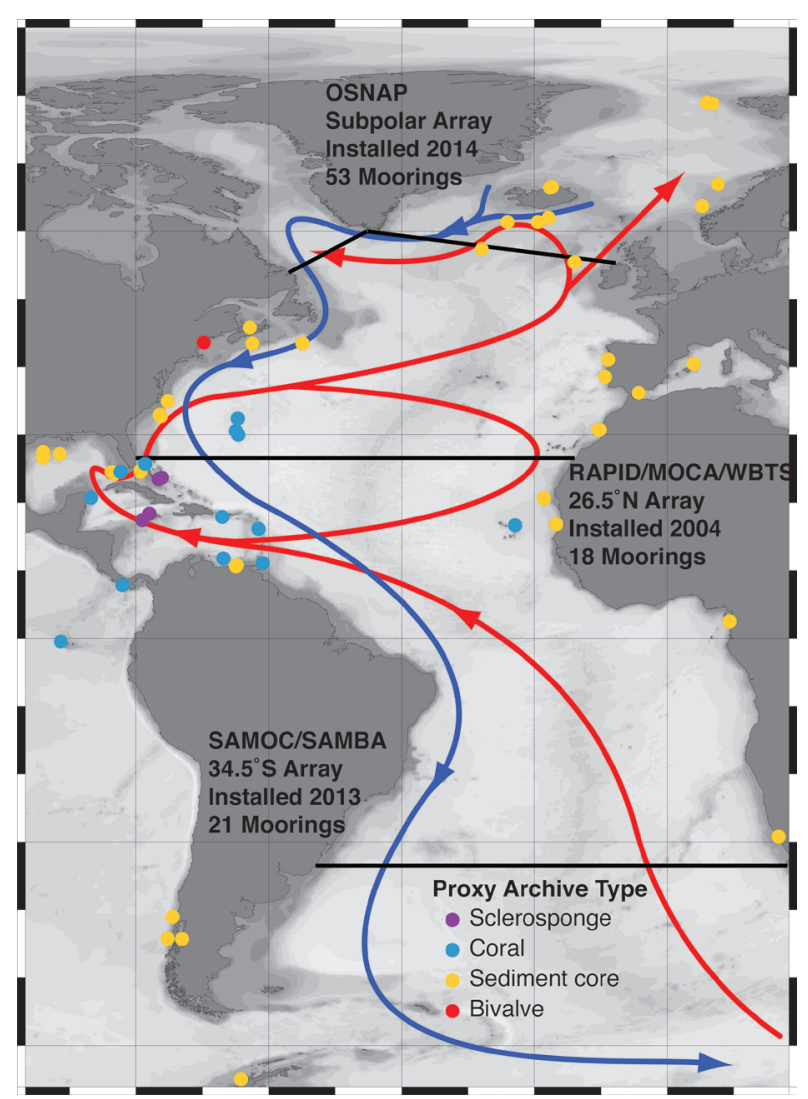

Figure 1: Location of existing paleoceanographic and modern oceanographic AMOC observing systems. Paleoceanographic sites represent the locations of samples/cores with paleotemperature information archived in the PAGES2k proxy temperature dataset version 2.0.0 (PAGES2k consortium, pers. comm.).

\section{A denser network of $A M O C$ and AMOC-related variables}

Iterating between observational data and models can be a powerful tool for improving mechanistic understanding of AMOC. Observations tell us how the system behaves and models provide a tool to explore how such behavior arises. Conversely, if different models have different mechanisms, we can use observations to constrain which model might have a more-realistic simulation of the process. The last 1000 years is a key target period because of (i) relatively abundant existing paleoclimate data to provide information about background climate; (ii) reasonably constrained climate forcing variables; (iii) the availability of annual or better resolution proxy archives, and (iv) the potential to overlap with the instrumental record to provide quantitative proxy calibrations. Such data-model comparisons, requiring an improved network of proxy records guided by process-based information from models, can be used to reliably characterize the past behavior of $\mathrm{AMOC}$, including the frequency and amplitude of decadal to centennial variability, as well as the response in associated environmental variables.

\section{Improved understanding and communication of uncertainties}

Cross-disciplinary coordination and cooperation could be facilitated if an effort was made to better quantify and report the uncertainties of our research. This issue came up repeatedly in reference to proxy reconstructions and calibrations, data assimilation projects, climate forcing factors used to drive models, and in data-model comparisons.

\section{Encourage coordination between scientific communities}

This may be accomplished at the level of individual researchers or larger organizations. Examples of the latter include adding a paleoceanography-specific team to the US AMOC/ UK RAPID working groups; reviving something similar to the former PAGES-CLIVAR Intersections program to focus on targeted workshops; and strengthening links between CMIP and PMIP.

\section{AFFILIATION}

Chesapeake Biological Laboratory, University of Maryland Center for Environmental Science, Solomons, USA

\section{CONTACT}

K. Halimeda Kilbourne: kilbourn@umces.edu REFERENCES

Alley RB (2007) Annu Rev Earth Planet Sci 35: 241-272 Buckley MW, Marshall J (2016) Revi Geophys 54: 5-63 Denton GH, Broecker WS (2008) Quat Sci Rev 27: 1939-1950 